\title{
Compendium of TCDD-mediated transcriptomic response datasets in mammalian model systems
}

Stephenie D. Prokopec ${ }^{1}$, Kathleen E. Houlahan ${ }^{1}$, Ren X. Sun ${ }^{1,2}$, John D. Watson ${ }^{1}$, Cindy Q. Yao ${ }^{1}$, Jamie Lee', Christine P'ng ${ }^{1}$, Renee Pang ${ }^{1}$, Alexander H. Wu', Lauren C. Chong ${ }^{1}$, Ashley B. Smith', Nicholas J. Harding ${ }^{1}$, Ivy D. Moffat ${ }^{2}$, Jere Lindén ${ }^{3}$, Sanna Lensu ${ }^{4,5}$, Allan B. Okey², Raimo Pohjanvirta ${ }^{6,7}$ and Paul C. Boutros ${ }^{1,2,8^{*}}$

\begin{abstract}
Background: 2,3,7,8-tetrachlorodibenzo-p-dioxin (TCDD) is the most potent congener of the dioxin class of environmental contaminants. Exposure to TCDD causes a wide range of toxic outcomes, ranging from chloracne to acute lethality. The severity of toxicity is highly dependent on the aryl hydrocarbon receptor (AHR). Binding of TCDD to the AHR leads to changes in transcription of numerous genes. Studies evaluating the transcriptional changes brought on by TCDD may provide valuable insight into the role of the AHR in human health and disease. We therefore compiled a collection of transcriptomic datasets that can be used to aid the scientific community in better understanding the transcriptional effects of ligand-activated AHR.

Results: Specifically, we have created a datasets package - TCDD.Transcriptomics - for the R statistical environment, consisting of 63 unique experiments comprising 377 samples, including various combinations of 3 species (human derived cell lines, mouse and rat), 4 tissue types (liver, kidney, white adipose tissue and hypothalamus) and a wide range of TCDD exposure times and doses. These datasets have been fully standardized using consistent preprocessing and annotation packages (available as of September 14, 2015). To demonstrate the utility of this R package, a subset of "AHR-core" genes were evaluated across the included datasets. Ahrr, Nqo1 and members of the Cyp family were significantly induced following exposure to TCDD across the studies as expected while Aldh3a1 was induced specifically in rat liver. Inmt was altered only in liver tissue and primarily by rat-AHR.

Conclusions: Analysis of the "AHR-core" genes demonstrates a continued need for studies surrounding the impact of AHR-activity on the transcriptome; genes believed to be consistently regulated by ligand-activated AHR show surprisingly little overlap across species and tissues. Until now, a comprehensive assessment of the transcriptome across these studies was challenging due to differences in array platforms, processing methods and annotation versions. We believe that this package, which is freely available for download (http://labs.oicr.on.ca/boutros-lab/tcddtranscriptomics) will prove to be a highly beneficial resource to the scientific community evaluating the effects of TCDD exposure as well as the variety of functions of the AHR.
\end{abstract}

Keywords: TCDD, AHR, Microarray datasets, $R$

\footnotetext{
* Correspondence: Paul.Boutros@oicr.on.ca

1 Informatics and Bio-computing Program, Ontario Institute for Cancer

Research, 661 University Avenue, Suite 510, Toronto, ON M5G 0A3, Canada

2Department of Pharmacology \& Toxicology, University of Toronto, Toronto,

Canada

Full list of author information is available at the end of the article
}

(c) The Author(s). 2017 Open Access This article is distributed under the terms of the Creative Commons Attribution 4.0 International License (http://creativecommons.org/licenses/by/4.0/), which permits unrestricted use, distribution, and reproduction in any medium, provided you give appropriate credit to the original author(s) and the source, provide a link to the Creative Commons license, and indicate if changes were made. The Creative Commons Public Domain Dedication waiver (http://creativecommons.org/publicdomain/zero/1.0/) applies to the data made available in this article, unless otherwise stated. 


\section{Background}

The aryl hydrocarbon receptor (AHR) is an evolutionarily conserved transcription factor [1] activated by small molecule binding. Prior to ligand-activation, the AHR resides in the cytoplasm bound to chaperone proteins, including heat shock protein 90 (HSP90) and the AHRinteracting protein (AIP) [2,3]. Ligand-activation of this receptor leads to translocation into the nucleus, dissociation of chaperones and dimerization with the AHR nuclear translocator (ARNT) [4]. The AHR: ARNT complex is able to bind DNA at recognized motifs known as aryl hydrocarbon response elements (AHREs) whereby transcription of the associated genes is regulated [5]. Modulation of AHR activity has been linked to various diseases, including numerous in vitro studies of breast [6-8], endometrial [9], kidney [10], lung [11, 12] and prostate [13] cancers and inflammatory skin [14] and bowel $[15,16]$ diseases.

Activation of the AHR can occur by both endogenous molecules, such as tryptophan metabolites [17], and exogenous molecules, such as polycyclic aromatic hydrocarbons. 2,3,7,8-tetrachlorodibenzo- $p$-dioxin (TCDD) is the most potent congener of chlorinated dioxins, a large class of environmental contaminants produced as a byproduct of various industrial processes [18]. Many of the toxic effects of TCDD exposure, including chloracne, immunosuppression, hepatotoxicity and cancer [19], are mediated by the AHR. Strong evidence for this relationship comes from studies of AHR-knockout mice [20-22], mice containing AHR-inactivating mutations [23-25] and conditional ARNT-null mice [26], all of which are unresponsive, or show reduced response, to TCDD. Differences in the toxic outcomes of TCDD occur across species and have been linked to polymorphisms in the AHR. A particularly TCDD-resistant strain of mice, DBA/ $2 \mathrm{~J}$, presents with an Ala375Val mutation within the $A H R$ gene; this leads to reduced affinity of the receptor for TCDD [27-29]. As another example, two strains of rat, Long-Evans (L-E) and Han/Wistar (H/W) show dramatic differences in TCDD susceptibility. These differences are primarily due to a point mutation that results in partial deletion of the transactivation domain of the $A H R$ in the TCDD-resistant $\mathrm{H} / \mathrm{W}$ rat [30]. Furthermore, inbred lines (Line $\mathrm{A} / \mathrm{B} / \mathrm{C}$ ) derived from $\mathrm{L}-\mathrm{E} \times \mathrm{H} / \mathrm{W}$ crosses demonstrate intermediate susceptibility to TCDD depending on AHR genotype [31]. In humans, the AHR gene most closely resembles that of the DBA/2 J mouse [29]. However, a number of polymorphisms have been identified within both the ligand-binding and transactivation domains of the human AHR [32] but the overall functional consequences of these polymorphisms are not yet clear. In addition to the differences in TCDD-response phenotypes among different mammals, TCDD exposure results in tissue-specific responses. In rats, TCDD tends to accumulate in liver, spleen, adipose tissue and pancreas [33]. The broadest spectrum of transcriptional responses in rodents is detected in liver [34]. Further compounding the issue, there is a sex-dependent element to the transcriptomic alterations evoked by TCDD [35-38].

Despite considerable study into the transcriptomic changes mediated by the TCDD: AHR complex that lead to the observed toxic outcomes, the specific genes and pathways responsible for these outcomes remain unknown. As such, a global resource describing transcriptomic changes following activation of the AHR across a wide variety of tissues and species would prove very useful to the scientific community. Therefore, we have generated such a resource consisting of transcriptomic data from numerous studies in our laboratory and others (a total of 377 samples) and we introduce the freelyavailable TCDD.Transcriptomics package for the $\mathrm{R}$ statistical environment.

\section{Implementation \\ Experimental methods}

The experimental design, animal handling and sample preparation for individual experiments are described elsewhere [34, 37-43]. Data from human Multipotent Adipose-Derived Stem (hMADS) cells (differentiated and undifferentiated; TCDD treated and control) were downloaded from NCBI's GEO repository (GSE32026) [42], as were data for primary human and female Sprague-Dawley (SD) rat hepatocyte cell lines (GSE14555) [44]. Array data for DBA/2 J mouse liver were generated in our laboratories as follows: briefly, adult male DBA/ $2 \mathrm{~J}$ mice were bred in the colonies of the National Public Health Institute, Division of Environmental Health, Kuopio, Finland. Study plans were approved by the Finnish National Animal Experiment Board (Eläinkoelautakunta, ELLA; permit code: ESLH-2008-07223/Ym23). Animals were housed singly in Makrolon cages with aspen chip bedding (Tapvei Oy, Kaavi, Finland) and provided with Altromin 1314 pellet feed (Altromin Spezialfutter $\mathrm{GmbH}$ \& Co. KG, Lage, Germany) and water available ad libitum. The housing environment was maintained at $21 \pm 1{ }^{\circ} \mathrm{C}$, with a relative humidity of $50 \pm 10 \%$ and a $12 \mathrm{~h}$ light cycle. TCDD ( 5 or $500 \mu \mathrm{g} / \mathrm{kg}$ dissolved in corn oil) or corn oil vehicle alone were administered by oral gavage $(10 \mathrm{~mL} / \mathrm{kg})$. Animals were euthanized by carbon dioxide, followed immediately by cardiac exsanguination $19 \mathrm{~h}$ following treatment. Livers were excised and frozen in liquid nitrogen. Tissue samples were shipped on dry ice to the analytic laboratory and stored at $-80{ }^{\circ} \mathrm{C}$.

Similarly, adult male transgenic "AHR-ratonized" mice, ages 12-23 weeks, were bred as above. Mice were housed singly in suspended, wire-mesh stainless-steel or Makrolon cages, with the housing environment maintained as 
described above. Animals were provided with R36 pellet feed (Lactamin, Stockholm, Sweden) and tap water available ad libitum. Animals $(\mathrm{n}=83)$ were divided into 5 groups per $A h r$ isoform (INS/DEL/rWT) and TCDD (125, 250, 500, or $1000 \mu \mathrm{g} / \mathrm{kg}$ dissolved in corn oil) or corn oil vehicle alone were administered by oral gavage $(10 \mathrm{~mL} / \mathrm{kg})$. Animals were euthanized by cervical dislocation 4 days following exposure. Tissue was collected and stored as above.

Animal handling and reporting comply with ARRIVE guidelines [45]. RNA isolation and microarray hybridization were performed as described elsewhere [37, 38, 46]. Remaining data were generated and deposited in the GEO repository as described in the original publications [34, 37-41, 43].

\section{Computational methods Human cell lines}

For hMADS cells, raw GenePix image data (.gpr files) were loaded into the $\mathrm{R}$ statistical environment (v3.2.1) using the limma (v3.24.13) package. Efforts were made to emulate the processing procedures conducted by the original authors: images were first cleaned by filtering out bad spots (flagged as "bad", "not found" or "absent" or known as $-100,-50$ and -75 respectively) by assigning those spots a weight of zero. Normalization was performed within arrays by applying global LOESS. Agilent Feature IDs were annotated with EntrezGene IDs and gene names using an annotation table obtained from NCBI's GEO repository for the array type (GPL4133). Linear modelling was conducted to identify genes with statistically significant differential mRNA abundances between TCDD-treated and reference samples. An empirical Bayes method was applied following model fitting to reduce standard error and moderated t-tests were used to assess statistical significance [47]. All $p$-values were adjusted for multiple testing using a $5 \%$ false discovery rate (FDR) [48]. Genes with multiple mapped Agilent Feature IDs were trimmed by keeping the feature ID with the lowest $p$-value.

For primary human hepatocyte cell line data, CEL files were downloaded from GEO (GSE14555) and loaded into the R statistical environment (v3.3.1) using the affy package (v1.48.0) of the BioConductor library [49]. Due to limited sample size, data for both sexes and all dose points were processed together. Data were normalized using the RMA algorithm [50] and probe annotations were obtained using the custom CDF [51] hgu133ahsentrezgcdf (v19.0.0) and database hgu133ahsentrezg_db (v19.0.0) packages. Probes were filtered using a background intensity threshold established by evaluating chromosome $\mathrm{Y}$ associated probes in female samples. Linear modelling was performed using the limma (v3.28.21) package, with contrasts fit to identify differences between treatment and control groups for each treatment dose. An empirical Bayes moderation of the standard error [47] was applied, and model-based t-tests were used to assess significance, accompanied by FDR correction for multiple testing [48].

\section{Mouse data}

Raw CEL files for livers from male and female C57BL/6 mice treated with TCDD or corn oil along a time-course (GSE61037) were loaded in the R statistical environment (v3.2.1) using the affy package (v1.46.1)as described above. Data for both sexes and all time points were preprocessed together and normalized using the RMA algorithm [50]. Probe annotations were obtained using the custom CDF [51] mogene11stmmentrezgcdf (v19.0.0) and database mogene11stmmentrezg_db (v19.0.0) packages. Chromosome $\mathrm{Y}$ probe filtering was performed as described above. Linear modelling was performed separately for each time point with both male and female samples using the limma (v3.24.13) package. An empirical Bayes moderation of the standard error [47] was applied, and model-based t-tests were used to assess significance, accompanied by FDR correction for multiple testing [48].

Data from the corresponding dose-response study were processed similarly with the following exceptions: male and female samples were preprocessed and modelled separately to avoid masking sex-specific effects at low dose treatments. As such, no additional probe filtering was performed. Similarly, transgenic "AHR-ratonized" mouse data were preprocessed and modelled independently for each AHR genotype with no additional probe filtering. Dose-response data from DBA/ $2 \mathrm{~J}$ mouse liver were processed and modelled as a single dataset using the above methods.

\section{Rat data}

For each experiment, raw CEL files were loaded in the $\mathrm{R}$ statistical environment (v3.2.1) using the affy package (v1.46.1) of the BioConductor library [49]. Rat adipose data (GSE18301) were preprocessed as a whole, including both strains and time points, using the RMA algorithm [50] with the custom rat2302rnentrezgcdf (v19.0.0) package [51]. Probes were further annotated with gene symbols and named using the rat2302rnentrezg_db (v19.0.0) package. Linear modelling was performed on all samples using the limma (v3.24.13) package, with contrasts fit to specify individual comparisons for both strains. Experiments at the day-1 timepoint evaluated TCDD relative to corn oil, whereas the 4-day experiment compared TCDD with feed-restricted, corn oil treated controls. As above, an empirical Bayes moderation of the standard error [47] was applied, and model-based t-tests were used to assess significance, 
accompanied by FDR correction for multiple testing [48]. Identical processing was performed for data generated from rat hypothalamus at $23 \mathrm{~h}$ (GSE61039) and rat liver at 4 and 10 day time points (GSE13513). Data from rat liver, 3 and $19 \mathrm{~h}$ time points (GSE10083), were processed together as described above using the custom rae230arnentrezgcdf (v19.0.0) package [51].

CEL files for the primary rat hepatocyte cell line dataset were downloaded from GEO (GSE14555) and loaded into the R statistical environment (v3.3.1) using the affy package (v1.48.0) of the BioConductor library [49]. Data were normalized using the RMA algorithm [50] and probe annotations were obtained using the custom CDF [51] rgu34arnentrezgcdf (v19.0.0) and database rgu34arnentrezg_db (v19.0.0) packages. As this specifc array type does not include probes for genes located on chromosome Y, no additional filtering was performed. Linear modelling was performed using the limma (v3.28.21) package, with contrasts fit to identify differences between treatment and control groups for each treatment dose. An empirical Bayes moderation of the standard error [47] was applied, and model-based t-tests were used to assess significance, accompanied by FDR correction for multiple testing [48].

\section{Interspecies comparisons}

All interspecies comparisons may be facilitated using homologene IDs provided by NCBI. A function is provided in the TCDD.Transcriptomics package to load filtered HomoloGene data (build 68) for comparison of mouse, rat and human transcriptomic responses to TCDD.

\section{Package access}

The TCDD.Transcriptomics package is available for download from http://labs.oicr.on.ca/boutros-lab/tcddtranscriptomics, along with instructions for direct download and installation within the $\mathrm{R}$ statistical environment. TCDD.Transcriptomics is designed for use with the $R$ statistical environment ( $\geq \mathrm{v} 2.10 .1)$ and is dependent on

Table 1 Summary of TCDD Datasets

\begin{tabular}{|c|c|c|c|c|c|c|c|}
\hline Species & Tissue & $\begin{array}{l}\text { Strain/AHR } \\
\text { Genotype }\end{array}$ & Sex & Number of Samples & Dose $(\mathrm{s})(\mu \mathrm{g} / \mathrm{kg})$ & Time(s) (hours) & GEO Accession \\
\hline \multirow[t]{2}{*}{ Human } & $\begin{array}{l}\text { adipose-derived stem } \\
\text { cells }\end{array}$ & hWT & $N / A$ & 8 & $25 \mathrm{nM}$ & 48 & GSE32026 \\
\hline & $\begin{array}{l}\text { primary hepatocyte } \\
\text { cell line }\end{array}$ & hWT & male and female & 3 & $\begin{array}{l}0.00001,0.001,0.01 \\
0.1,1,10,316(\mathrm{nM})\end{array}$ & 48 & GSE14555 \\
\hline \multirow[t]{9}{*}{ Mouse } & \multirow[t]{2}{*}{ kidney } & C57BL/6 & male & 12 & \multirow[t]{2}{*}{0,1000} & \multirow[t]{2}{*}{19} & \multirow[t]{2}{*}{ GSE15857 } \\
\hline & & AHR-KO & male & 6 & & & \\
\hline & \multirow[t]{7}{*}{ liver } & C57BL/6 & male & 62 & \multirow[t]{2}{*}{$0,125,250,500,1000$} & $6,19,24,72,96,144$ & $\begin{array}{l}\text { GSE15858 } \\
\text { GSE61037 } \\
\text { GSE61038 }\end{array}$ \\
\hline & & & female & 47 & & $6,24,72,96,144$ & $\begin{array}{l}\text { GSE61037 } \\
\text { GSE61038 }\end{array}$ \\
\hline & & $\mathrm{DBA} / 2$ & male & 12 & $0,5,500$ & 19 & NA \\
\hline & & AHR-KO & male & 6 & 0,1000 & 19 & GSE15858 \\
\hline & & rWT (L-E) & male & 17 & $0,125,250,500,1000$ & 96 & GSE72270 \\
\hline & & DEL $(H / W)$ & male & 21 & & & \\
\hline & & INS $(H / W)$ & male & 22 & & & \\
\hline \multirow[t]{9}{*}{ Rat } & \multirow[t]{2}{*}{ adipose } & $L-E$ & male & 20 & \multirow[t]{8}{*}{0,100} & 24,96 & GSE18301 \\
\hline & & $\mathrm{H} / \mathrm{W}$ & male & 8 & & 24 & \\
\hline & \multirow[t]{2}{*}{ hypothalamus } & $L-E$ & male & 7 & & \multirow[t]{2}{*}{23} & \multirow[t]{2}{*}{ GSE61039 } \\
\hline & & $\mathrm{H} / \mathrm{W}$ & male & 8 & & & \\
\hline & \multirow[t]{4}{*}{ liver } & $L-E$ & male & 39 & & \multirow[t]{2}{*}{$3,19,96,240$} & \multirow{2}{*}{$\begin{array}{l}\text { GSE10083 } \\
\text { GSE13513 }\end{array}$} \\
\hline & & $\mathrm{H} / \mathrm{W}$ & male & 30 & & & \\
\hline & & $\operatorname{Ln}-\mathrm{A}(\mathrm{H} / \mathrm{W})$ & male & 8 & & \multirow[t]{2}{*}{19} & \multirow[t]{2}{*}{ GSE10083 } \\
\hline & & $\operatorname{Ln}-\mathrm{C}(\mathrm{L}-\mathrm{E})$ & male & 8 & & & \\
\hline & $\begin{array}{l}\text { primary hepatocyte } \\
\text { cell line }\end{array}$ & rWT (SD) & female & 14 & $\begin{array}{l}0.00001,0.001,0.01 \\
0.1,1,10,316(\mathrm{nM})\end{array}$ & 48 & GSE14555 \\
\hline
\end{tabular}

A total of 63 datasets are included in this package consisting of 377 samples across 3 species, 4 tissue types and a wide range of AHR genotypes, TCDD exposure times and doses 
the BoutrosLab.plotting.general (BPG) package ( $\geq$ v3.10.2) (P'ng et al., submitted) for production of plotting covariates and easy integration with data visualizations. The BPG package can be found here: http://labs.oicr.on.ca/boutroslab/software/bpg.

\section{Results and Discussion}

In recent years, activation of the AHR has become the focus of myriad studies across a wide range of fields. In particular, significant effort has gone into elucidating the mechanism by which TCDD activation of the AHR leads to a diversity of toxic outcomes. As the ligand-activated AHR is a transcription factor, the transcriptome has been the primary focus of these studies. As such, we have collated a number of transcriptomic datasets arising from various TCDD exposure studies in rats, mice and human cell lines (Table 1, Additional file 1) into a datasets package for the $\mathrm{R}$ statistical environment. Specifically, microarray data from 12 separate studies covering 63 unique experimental conditions were collected. Data were generated using two microarray platforms and seven unique array types: Agilent's Whole Human Genome Microarray and Affymetrix's Human Genome U133A Array, Rat Expression Array (230A), Rat Genome U34 and 2302.0 Arrays, Mouse Genome 4302.0 Array and Mouse Gene 1.1 ST Array. Data from Affymetrix arrays were processed using the RMA algorithm with the most recent probe to EntrezGeneID map (as described in Materials and Methods), analyzed using linear modelling, FDR-corrected for multiple testing and results formatstandardized.

Each dataset is labelled with a highly descriptive title, indicating the species, strain, tissue type, length of exposure (hours), TCDD dose $(\mu \mathrm{g} / \mathrm{kg}$ ) and sex (male if unlabelled) from which the data were generated. Furthermore, each dataset contains three parts: the sample information, preprocessed data and analysis results. First, the sample information file outlines the type and treatment conditions for each sample in the experiment. The second file contains the expression data and consists of the normalized array data for all samples listed in the sample information file. Finally, the results file outlines the magnitude and significance of change as determined by linear modelling for each gene available on the array. In this file, all genes are annotated with EntrezGene IDs, gene symbol and full gene name.

To provide an example of the usefulness of this $\mathrm{R}$ package, a set of widely recognized "AHR-core" genes, genes with mRNA transcription known to be regulated by the AHR transcription factor in a wide range of species and tissues [52-57], were visualized across the available datasets (Fig. 1). Data was extracted according to Homologene ID in order to ensure the suitability of comparisons across species. Interestingly, while most of the selected genes

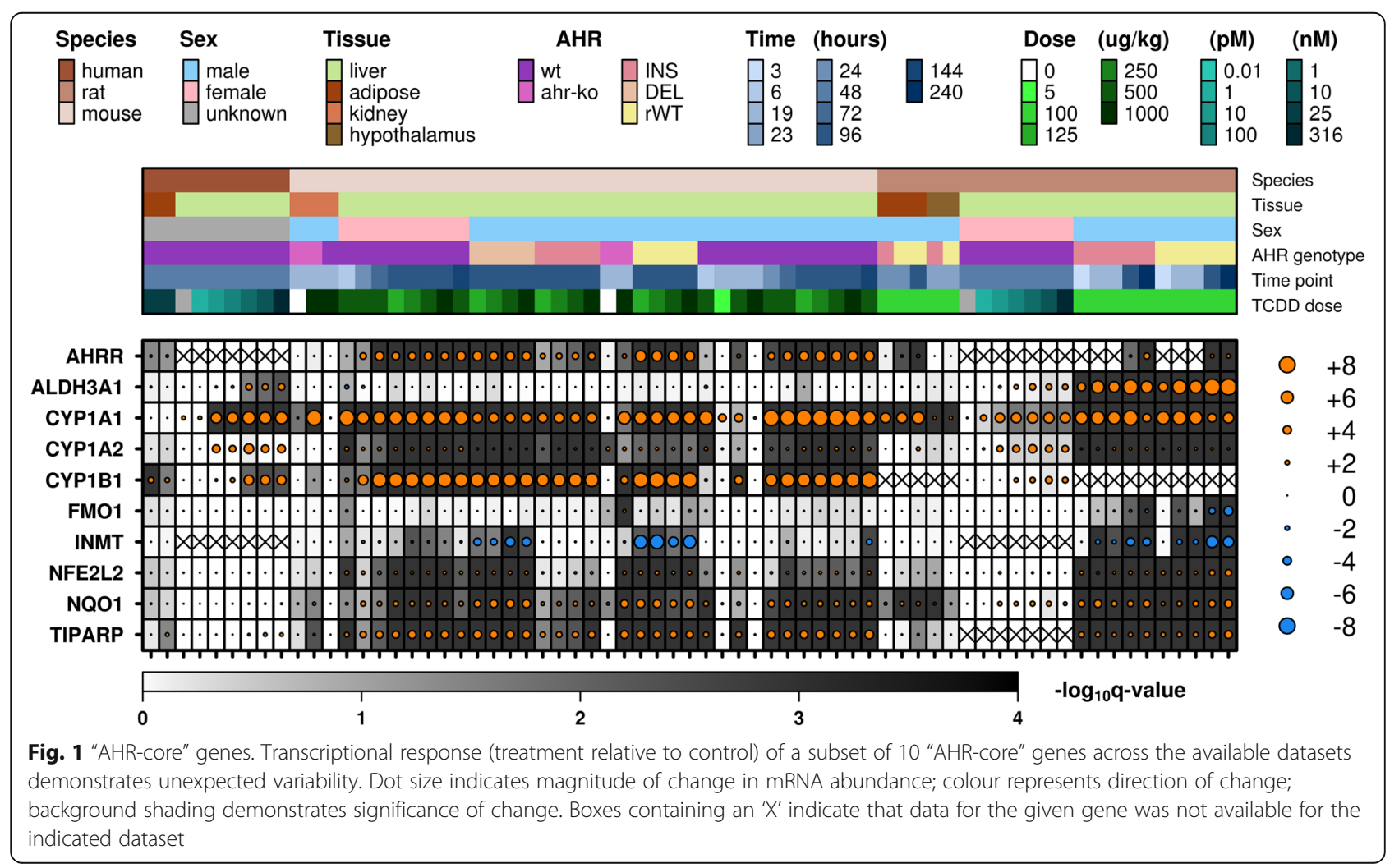


show some degree of TCDD-mediated change in transcript levels across the datasets, some genes demonstrate a species and/or tissue specific effect. In particular, ALDH3A1 appears to be induced only in rat liver and primary human hepatocytes. Similarly, INMT is repressed in livers of rats and TCDD-sensitive "AHR-ratonized" mice. The variability in response to the "AHR-core" genes highlights the need for further study into the effects of TCDD on various organisms.

While the TCDD.Transcriptomics package provides access to a wide range of datasets, it is by no means fully comprehensive. The GEO repository contains a number of additional datasets relating to array-based mRNA abundance studies of TCDD-mediated transcriptional regulation, however these typically pertain to gestational exposure in mice and rats, human cancer-derived cell lines and zebra fish - all of which are beyond the current scope of this package but may be incorporated at a later date.

\section{Conclusion}

Here we have produced a standardized compendium of TCDD-mediated transcriptional changes for use in the $\mathrm{R}$ statistical environment. This package, titled TCDD.Transcripomics, contains data from 63 experiments including 377 samples, incorporating data from 3 species, 4 tissue types, both sexes and a wide range of AHR genotypes, TCDD exposure times and doses, along with an up-todate HomoloGene dataset for interspecies comparison, and is freely available for download (http://labs.oicr.on.ca/ boutros-lab/tcdd-transcriptomics). This datasets package will provide a significant resource for the scientific community encompassing a variety of fields of study, from toxicological studies concerning TCDD and dioxins to studies of the AHR and its role in normal physiology and human disease.

\section{Availability and requirements}

Project name: TCDD Transcriptomics

Project home page: http://labs.oicr.on.ca/boutros-lab/ tcdd-transcriptomics

Operating system(s): tested on Ubuntu and Debian

Programming language: $R$

Other requirements: depends on BPG (http://labs.oicr.on.ca/ boutros-lab/software/bpg)

Licence: GPL-2

\section{Additional file}

Additional file 1: Overview of Included TCDD Datasets. (XLSX 16 kb)

\section{Abbreviations}

AHR: Aryl hydrocarbon receptor; H/W: Han/Wistar (Kuopio); hMADS: Human Multipotent Adipose-Derived Stem; L-E: Long-Evans (Turku/AB); SD: Sprague Dawley; TCDD: 2,3,7,8-Tetrachlorodibenzo-p-dioxin

\section{Acknowledgements}

The authors thank all members of the Boutros Lab, as well as Dr. Patricia Harper, Kirsten Bielefeld and Hanbo Chen, for excellent technical assistance and support.

\section{Funding}

This work was supported by the Canadian Institutes of Health Research (grant number MOP-57903 to ABO and PCB), the Academy of Finland (grant number 261232 to RP), and with the support of the Ontario Institute for Cancer Research to PCB through funding provided by the Government of Ontario. PCB was supported by a Terry Fox Research Institute New Investigator Award and a CIHR New Investigator Award. The study sponsors had no role in the study design; in the collection, analysis and interpretation of data; in the writing of the report; and in the decision to submit the paper for publication.

\section{Availability of data and material}

The TCDD Transcriptomics datasets package is freely available for download (http://labs.oicr.on.ca/boutros-lab/tcdd-transcriptomics). Additionally, the original datasets supporting the results of this article are publicly available on NCBI's GEO repository: L-E and H/W rat hypothalamus (GSE61039), adipose (GSE18301) and liver at 3 and $19 \mathrm{~h}$ (GSE10083), 4 and 10 days (GSE13513); human multipotent adipose-derived stem cells (GSE32026); AHR-null and wild-type mouse liver (GSE15858) and kidney (GSE15857); male and female C57BL/6 mice along a time-course (GSE61037) and dose response (GSE61038); AHR-ratonized mice (GSE72270); primary human hepatocyte and primary rat hepatocyte cell lines (GSE14555).

\section{Authors' contributions}

$J \mathrm{~L}, \mathrm{SL}$ and RP carried out and supervised animal experiments. IDM, JDW, SDP and ABS performed sample preparation for mouse and rat transcriptomic analyses. SDP, KEH, RXS and JL performed statistical and bioinformatics analyses. SDP wrote the first draft of the manuscript. CQY, CP, RPang, LCC and $\mathrm{NJH}$ generated tools and reagents. $A B O, R P$ and $P C B$ initiated the project and supervised research. All authors approved the manuscript.

\section{Competing interests}

The authors declare that they have no competing interests.

\section{Consent for publication}

Not applicable

\section{Ethics approval and consent to participate}

Not applicable

\section{Author details \\ ${ }^{1}$ Informatics and Bio-computing Program, Ontario Institute for Cancer Research, 661 University Avenue, Suite 510, Toronto, ON M5G 0A3, Canada. ${ }^{2}$ Department of Pharmacology \& Toxicology, University of Toronto, Toronto, Canada. ${ }^{3}$ Department of Veterinary Biosciences, University of Helsinki, Helsinki, Finland. ${ }^{4}$ Department of Biology of Physical Activity, University of Jyväskylä, Jyväskylä, Finland. ${ }^{5}$ Department of Environmental Health, National Institute for Health and Welfare, Kuopio, Finland. 'Laboratory of Toxicology, National Institute for Health and Welfare, Kuopio, Finland. ${ }^{7}$ Department of Food Hygiene and Environmental Health, University of Helsinki, Helsinki, Finland. ${ }^{8}$ Department of Medical Biophysics, University of Toronto, Toronto, Canada.}

Received: 23 July 2016 Accepted: 20 December 2016

Published online: 13 January 2017

\section{References}

1. Hahn ME, Karchner SI, Shapiro MA, Perera SA. Molecular evolution of two vertebrate aryl hydrocarbon (dioxin) receptors (AHR1 and AHR2) and the PAS family. Proc Natl Acad Sci U S A. 1997;94(25):13743-8.

2. Rowlands JC, Gustafsson JA. Aryl hydrocarbon receptor-mediated signal transduction. Crit Rev Toxicol. 1997;27(2):109-34.

3. Petrulis JR, Perdew GH. The role of chaperone proteins in the aryl hydrocarbon receptor core complex. Chem Biol Interact. 2002;141(1-2):25-40.

4. Reyes H, Reisz-Porszasz S, Hankinson O. Identification of the Ah receptor nuclear translocator protein (Arnt) as a component of the DNA binding form of the Ah receptor. Science. 1992;256(5060):1193-5. 
5. Shen ES, Whitlock Jr JP. Protein-DNA interactions at a dioxin-responsive enhancer. Mutational analysis of the DNA-binding site for the liganded Ah receptor. J Biol Chem. 1992;267(10):6815-9.

6. Goode GD, Ballard BR, Manning HC, Freeman ML, Kang Y, Eltom SE. Knockdown of aberrantly upregulated aryl hydrocarbon receptor reduces tumor growth and metastasis of MDA-MB-231 human breast cancer cell line. Int J Cancer. 2013;133(12):2769-80.

7. Saito R, Miki Y, Hata S, Takagi K, lida S, Oba Y, Ono K, Ishida T, Suzuki T, Ohuchi $\mathrm{N}$, et al. Aryl hydrocarbon receptor in breast cancer-a newly defined prognostic marker. Horm Cancer. 2014;5(1):11-21.

8. Salisbury TB, Tomblin JK, Primerano DA, Boskovic G, Fan J, Mehmi I, Fletcher J, Santanam N, Hurn E, Morris GZ, et al. Endogenous aryl hydrocarbon receptor promotes basal and inducible expression of tumor necrosis factor target genes in MCF-7 cancer cells. Biochem Pharmacol. 2014;91(3):390-9.

9. Qu XL, Wang SY, Jia YJ, Guan Y. Aryl hydrocarbon receptor exogenous ligand 3-methylchoranthrene inhibited endometrial cancer cells proliferation. Eur Rev Med Pharmacol Sci. 2014;18(8):1269-76.

10. Ishida M, Mikami S, Shinojima T, Kosaka T, Mizuno R, Kikuchi E, Miyajima A, Okada Y, Oya M. Activation of aryl hydrocarbon receptor promotes invasion of clear cell renal cell carcinoma and is associated with poor prognosis and cigarette smoke. Int J Cancer. 2015;137(2):299-310.

11. Su JM, Lin P, Chang H. Prognostic value of nuclear translocation of aryl hydrocarbon receptor for non-small cell lung cancer. Anticancer Res. 2013; 33(9):3953-61.

12. Spink BC, Bloom MS, Wu S, Sell S, Schneider E, Ding X, Spink DC. Analysis of the AHR gene proximal promoter GGGGC-repeat polymorphism in lung, breast, and colon cancer. Toxicol Appl Pharmacol. 2015;282(1):30-41.

13. Richmond O, Ghotbaddini M, Allen C, Walker A, Zahir S, Powell JB. The ary hydrocarbon receptor is constitutively active in advanced prostate cancer cells. PLoS One. 2014;9(4), e95058.

14. Kim HO, Kim JH, Chung BY, Choi MG, Park CW. Increased expression of the aryl hydrocarbon receptor in patients with chronic inflammatory skin diseases. Exp Dermatol. 2014;23(4):278-81.

15. Furumatsu K, Nishiumi S, Kawano Y, Ooi M, Yoshie T, Shiomi Y, Kutsumi H, Ashida H, Fujii-Kuriyama Y, Azuma T, et al. A role of the aryl hydrocarbon receptor in attenuation of colitis. Dig Dis Sci. 2011;56(9):2532-44.

16. Monteleone I, Rizzo A, Sarra M, Sica G, Sileri P, Biancone L, MacDonald TT, Pallone F, Monteleone G. Aryl hydrocarbon receptor-induced signals upregulate $I L-22$ production and inhibit inflammation in the gastrointestinal tract. Gastroenterology. 2011;141(1):237-48. 248 e231.

17. Heath-Pagliuso S, Rogers WJ, Tullis K, Seidel SD, Cenijn PH, Brouwer A, Denison MS. Activation of the Ah receptor by tryptophan and tryptophan metabolites. Biochemistry. 1998;37(33):11508-15.

18. Schecter A, Birnbaum L, Ryan JJ, Constable JD. Dioxins: an overview. Environ Res. 2006;101(3):419-28.

19. Kransler KM, McGarrigle BP, Olson JR. Comparative developmental toxicity of 2,3,7,8-tetrachlorodibenzo-p-dioxin in the hamster, rat and guinea pig. Toxicology. 2007;229(3):214-25

20. Schmidt JV, Su GH, Reddy JK, Simon MC, Bradfield CA. Characterization of a murine Ahr null allele: involvement of the Ah receptor in hepatic growth and development. Proc Natl Acad Sci U S A. 1996:93(13):6731-6.

21. Fernandez-Salguero PM, Hilbert DM, Rudikoff S, Ward JM, Gonzalez FJ. Arylhydrocarbon receptor-deficient mice are resistant to 2,3,7,8-tetrachlorodibenzo-pdioxin-induced toxicity. Toxicol Appl Pharmacol. 1996;140(1):173-9.

22. Mimura J, Yamashita K, Nakamura K, Morita M, Takagi TN, Nakao K, Ema M, Sogawa K, Yasuda M, Katsuki M, et al. Loss of teratogenic response to 2,3,7,8-tetrachlorodibenzo-p-dioxin (TCDD) in mice lacking the Ah (dioxin) receptor. Genes Cells. 1997;2(10):645-54

23. Bunger MK, Moran SM, Glover E, Thomae TL, Lahvis GP, Lin BC, Bradfield CA. Resistance to 2,3,7,8-tetrachlorodibenzo-p-dioxin toxicity and abnormal liver development in mice carrying a mutation in the nuclear localization sequence of the aryl hydrocarbon receptor. J Biol Chem. 2003;278(20):17767-74.

24. Walisser JA, Bunger MK, Glover E, Harstad EB, Bradfield CA. Patent ductus venosus and dioxin resistance in mice harboring a hypomorphic Arnt allele. J Biol Chem. 2004;279(16):16326-31.

25. Bunger MK, Glover E, Moran SM, Walisser JA, Lahvis GP, Hsu EL, Bradfield CA. Abnormal liver development and resistance to 2,3,7,8-tetrachlorodibenzo-pdioxin toxicity in mice carrying a mutation in the DNA-binding domain of the aryl hydrocarbon receptor. Toxicol Sci. 2008;106(1):83-92.

26. Nukaya M, Walisser JA, Moran SM, Kennedy GD, Bradfield CA. Aryl hydrocarbon receptor nuclear translocator in hepatocytes is required for aryl hydrocarbon receptor-mediated adaptive and toxic responses in liver. Toxicol Sci. 2010;118(2):554-63.

27. Chapman DE, Schiller CM. Dose-related effects of 2,3,7,8-tetrachlorodibenzop-dioxin (TCDD) in C57BL/6 J and DBA/2 J mice. Toxicol Appl Pharmacol. 1985;78(1):147-57.

28. Okey AB, Vella LM, Harper PA. Detection and characterization of a low affinity form of cytosolic Ah receptor in livers of mice nonresponsive to induction of cytochrome P1-450 by 3-methylcholanthrene. Mol Pharmacol. 1989;35(6):823-30

29. Ema M, Ohe N, Suzuki M, Mimura J, Sogawa K, Ikawa S, Fujii-Kuriyama Y Dioxin binding activities of polymorphic forms of mouse and human arylhydrocarbon receptors. J Biol Chem. 1994;269(44):27337-43.

30. Pohjanvirta R, Wong JM, Li W, Harper PA, Tuomisto J, Okey AB. Point mutation in intron sequence causes altered carboxyl-terminal structure in the aryl hydrocarbon receptor of the most 2,3,7,8-tetrachlorodibenzo-pdioxin-resistant rat strain. Mol Pharmacol. 1998;54(1):86-93.

31. Tuomisto JT, Viluksela M, Pohjanvirta R, Tuomisto J. The AH receptor and a novel gene determine acute toxic responses to TCDD: segregation of the resistant alleles to different rat lines. Toxicol Appl Pharmacol. 1999;155(1):71-81.

32. Rowlands CJ, Staskal DF, Gollapudi B, Budinsky R. The human AHR: identification of single nucleotide polymorphisms from six ethnic populations. Pharmacogenet Genomics. 2010;20(5):283-90.

33. Pohjanvirta R, Vartiainen T, Uusi-Rauva A, Monkkonen J, Tuomisto J. Tissue distribution, metabolism, and excretion of 14C-TCDD in a TCDD-susceptible and a TCDD-resistant rat strain. Pharmacol Toxicol. 1990;66(2):93-100.

34. Houlahan KE, Prokopec SD, Sun RX, Moffat ID, Linden J, Lensu S, Okey AB, Pohjanvirta R, Boutros PC. Transcriptional profiling of rat white adipose tissue response to 2,3,7,8-tetrachlorodibenzo-rho-dioxin. Toxicol Appl Pharmacol. 2015.

35. Enan E, Overstreet JW, Matsumura F, VandeVoort CA, Lasley BL. Gender differences in the mechanism of dioxin toxicity in rodents and in nonhuman primates. Reprod Toxicol. 1996;10(5):401-11.

36. Pohjanvirta $\mathrm{R}$. Transgenic mouse lines expressing rat $\mathrm{AH}$ receptor variants-a new animal model for research on $\mathrm{AH}$ receptor function and dioxin toxicity mechanisms. Toxicol Appl Pharmacol. 2009;236(2):166-82.

37. Prokopec SD, Watson JD, Lee J, Pohjanvirta R, Boutros PC. Sex-related differences in murine hepatic transcriptional and proteomic responses to TCDD. Toxicol Appl Pharmacol. 2015;284(2):188-96.

38. Lee J, Prokopec SD, Watson JD, Sun RX, Pohjanvirta R, Boutros PC. Male and female mice show significant differences in hepatic transcriptomic response to 2,3,7,8-tetrachlorodibenzo-p-dioxin. BMC Genomics. 2015;16(1):625.

39. Boutros PC, Bielefeld KA, Pohjanvirta R, Harper PA. Dioxin-dependent and dioxin-independent gene batteries: comparison of liver and kidney in AHRnull mice. Toxicol Sci. 2009;112(1):245-56.

40. Moffat ID, Boutros PC, Chen H, Okey AB, Pohjanvirta R. Aryl hydrocarbon receptor (AHR)-regulated transcriptomic changes in rats sensitive or resistant to major dioxin toxicities. BMC Genomics. 2010;11:263.

41. Boutros PC, Yao CQ, Watson JD, Wu AH, Moffat ID, Prokopec SD, Smith AB, Okey $A B$, Pohjanvirta R. Hepatic transcriptomic responses to TCDD in dioxinsensitive and dioxin-resistant rats during the onset of toxicity. Toxicol Appl Pharmacol. 2011;251(2):119-29.

42. Kim MJ, Pelloux V, Guyot E, Tordjman J, Bui LC, Chevallier A, Forest C, Benelli C, Clement K, Barouki R. Inflammatory pathway genes belong to major targets of persistent organic pollutants in adipose cells. Environ Health Perspect. 2012;120(4):508-14.

43. Houlahan KE, Prokopec SD, Moffat ID, Linden J, Lensu S, Okey AB, Pohjanvirta $\mathrm{R}$, Boutros PC. Transcriptional profiling of rat hypothalamus response to 2,3,7,8tetrachlorodibenzo-rho-dioxin. Toxicology. 2014;328C:93-101.

44. Carlson EA, McCulloch C, Koganti A, Goodwin SB, Sutter TR, Silkworth JB. Divergent transcriptomic responses to aryl hydrocarbon receptor agonists between rat and human primary hepatocytes. Toxicol Sci. 2009;112(1):257-72.

45. Kilkenny C, Browne WJ, Cuthill IC, Emerson M, Altman DG. Improving bioscience research reporting: the ARRIVE guidelines for reporting animal research. PLoS Biol. 2010;8(6), e1000412.

46. Prokopec SD, Buchner NB, Fox NS, Chong LC, Mak DY, Watson JD, Petronis A, Pohjanvirta R, Boutros PC. Validating reference genes within a mouse model system of 2,3,7,8-tetrachlorodibenzo-p-dioxin (TCDD) toxicity. Chem Biol Interact. 2013;205(1):63-71.

47. Smyth GK. Linear models and empirical bayes methods for assessing differential expression in microarray experiments. Stat Appl Genet Mol Biol. 2004;3:Article3.

48. Storey JD, Tibshirani R. Statistical significance for genomewide studies. Proc Natl Acad Sci U S A. 2003;100(16):9440-5. 
49. Gentleman RC, Carey VJ, Bates DM, Bolstad B, Dettling M, Dudoit S, Ellis B, Gautier L, Ge Y, Gentry J, et al. Bioconductor: open software development for computational biology and bioinformatics. Genome Biol. 2004;5(10):R80.

50. Irizarry RA, Hobbs B, Collin F, Beazer-Barclay YD, Antonellis KJ, Scherf U, Speed TP. Exploration, normalization, and summaries of high density oligonucleotide array probe level data. Biostatistics. 2003;4(2):249-64.

51. Dai M, Wang P, Boyd AD, Kostov G, Athey B, Jones EG, Bunney WE, Myers RM, Speed TP, Akil H, et al. Evolving gene/transcript definitions significantly alter the interpretation of GeneChip data. Nucleic Acids Res. 2005;33(20), e175.

52. Boutros PC, Yan R, Moffat ID, Pohjanvirta R, Okey AB. Transcriptomic responses to 2,3,7,8-tetrachlorodibenzo-p-dioxin (TCDD) in liver: comparison of rat and mouse. BMC Genomics. 2008;9:419.

53. Forgacs AL, Dere E, Angrish MM, Zacharewski TR. Comparative analysis of temporal and dose-dependent TCDD-elicited gene expression in human, mouse, and rat primary hepatocytes. Toxicol Sci. 2013;133(1):54-66.

54. Nebert DW, Roe AL, Dieter MZ, Solis WA, Yang Y, Dalton TP. Role of the aromatic hydrocarbon receptor and [Ah] gene battery in the oxidative stress response, cell cycle control, and apoptosis. Biochem Pharmacol. 2000;59(1):65-85.

55. Tijet N, Boutros PC, Moffat ID, Okey AB, Tuomisto J, Pohjanvirta R. Aryl hydrocarbon receptor regulates distinct dioxin-dependent and dioxinindependent gene batteries. Mol Pharmacol. 2006;69(1):140-53.

56. Yeager RL, Reisman SA, Aleksunes LM, Klaassen CD. Introducing the "TCDDinducible AhR-Nrf2 gene battery". Toxicol Sci. 2009;111(2):238-46.

57. Watson JD, Prokopec SD, Smith AB, Okey AB, Pohjanvirta R, Boutros PC. TCDD dysregulation of 13 AHR-target genes in rat liver. Toxicol Appl Pharmacol. 2014;274(3):445-54

\section{Submit your next manuscript to BioMed Central and we will help you at every step:}

- We accept pre-submission inquiries

- Our selector tool helps you to find the most relevant journal

- We provide round the clock customer support

- Convenient online submission

- Thorough peer review

- Inclusion in PubMed and all major indexing services

- Maximum visibility for your research

Submit your manuscript at www.biomedcentral.com/submit

C) Biomed Central 